\title{
Degree Operators and Scope
}

\author{
Irene Heim \\ Massachusetts Institute of Technology
}

\section{Introduction}

A familiar idea about gradable adjectives is that they denote relations between individuals and degrees. This is most transparent in constructions like (1), where we seem to be witnessing explicit reference to or quantification over degrees.
a. John is six feet tall.
b. He is that tall.
c. How tall is he?
d. However tall he is, ...

A sentence like (1)a can be analyzed very simply: tall denotes a relation between physical objects and degrees of height, John and six feet denote respectively an individual and a degree, and the whole thing (ignoring the vacuous copula) is hierarchically structured and compositionally interpreted just like an ordinary transitive sentence. The adjective's degree argument appears to be syntactically projected, just like the individual argument, and interpreted in an analogous fashion.

Argument positions where an individual is selected may be occupied by referential DPs as well as by quantificational DPs. How about argument positions for degrees? Do we also sometimes find quantificational degree arguments in the same slots as referential ones? This indeed is a plausible diagnosis of what goes on in gradation constructions like (2).
a. He is more than 4 feet tall.
b. He is taller than 4 feet.
c. He is taller than the bed is long.
d. He is as tall as you are.
e. He is tallest.
f. He is too tall.

(2)a, for example, could be paraphrased as 'he is tall to some degree exceeding 4 feet', with an explicit indefinite description (existential quantifier) over degrees. This kind of analysis can be given for all these examples: the underlined phrase in each example is a generalized quantifier over degrees that is generated in the same argument position occupied by the degree name six feet in (1)a. In those cases where that phrase is superficially discontinuous, we can attribute this to an (obligatory) superficial extraposition process which does not feed LF. ${ }^{1}$

Quantificational DPs are not always interpretable in the argument positions where they are generated, and so they move, sometimes covertly, to 
appropriate scope positions. There are island constraints on this movement, but within their limits, a certain amount of freedom. Sometimes a DP-quantifier has more than one available landing-site, and sometimes this choice gives rise to truth-conditional ambiguities (known as "scope ambiguities"). Does the analogy between individual and degree arguments extend to this phenomenon as well? Do we find ambiguities that are due to multiple scope options for degree quantifiers like the ones in (2)? This is the question I want to address in this paper.

In doing so, I will follow in the footsteps of Christopher Kennedy, who discussed the same question in his 1997 thesis. Kennedy came to a negative conclusion. He argued that the putative degree quantifiers in comparative constructions always take the narrowest possible scope - even when no known locality condition would seem to prevent them from scoping over another operator in their vicinity. He suggests that this fact is unexpected and mysterious if the constructions in question really do contain a constituent that is a degree quantifier and moves for interpretability. For this (and other) reasons he endorses a different LF-constituency (and semantics) for gradation structures, in which there is no degree-quantifier that needs to or is able to move in the first place.

My aim in this paper is modest and merely descriptive. I want to argue that the facts are more complicated than Kennedy concluded. In a limited set of environments, the multiple scope-options anticipated by the approach I have sketched do show up as truth-conditional ambiguities. Moreover, the interpretive options for various kinds of elided or implicit material give indirect evidence for two possible scope constellations even in certain cases where they truthconditionally collapse. I will tentatively conclude that gradation constructions do contain degree quantifiers that take scope by movement, though this movement is subject to (severe) syntactic constraints. I have no proposal yet about the nature of these constraints.

Let me begin by presenting a more concrete version of the degreequantifier analysis of comparatives that $I$ have hinted at. Unfortunately, quite a few distinct variants are suggested by the existing literature on comparatives, and I do not have space in this paper to motivate the specific choices I make or to prove that they don't affect my points. I will assume that gradable adjectives denote functions of type $<\mathrm{d}, \mathrm{et}>^{2}$ which are monotone in the sense of (3). A sample lexical entry is (4).

$$
\begin{aligned}
& \text { A function } \mathrm{f} \text { of type }<\mathrm{d} \text {,et }>\text { is monotone iff } \\
& \forall \mathrm{x} \forall \mathrm{d} \forall \mathrm{d}^{\prime}\left[\mathrm{f}(\mathrm{d})(\mathrm{x})=1 \& \mathrm{~d}^{\prime}<\mathrm{d} \rightarrow \mathrm{f}\left(\mathrm{d}^{\prime}\right)(\mathrm{x})=1\right]
\end{aligned}
$$

$\llbracket$ tall $\rrbracket=\lambda \mathrm{d}_{\mathrm{d}} \cdot \lambda \mathrm{x}_{\mathrm{e}} \cdot \mathrm{x}$ is tall to degree $\mathrm{d}$

The adjective's degree argument is its inner argument; it is syntactically projected as sister to $\mathrm{A}$ and will be labeled DegP. ${ }^{3}$ In the simplest kind of case (e.g. (1)a,b), the DegP has a meaning of type $d$ and is straightforwardly interpretable in situ (by functional application). In the more complicated cases which we will mostly be concerned with, the DegP is a generalized quantifier over degrees (type $<\mathrm{dt}, \mathrm{t}>$ ). This is the case for complex DegPs headed by -er, as, too etc., e.g., -er than 6 
feet, -er than Mary is tall, 5 inches -er than that. I will abstract away as much as possible from issues concerning the internal structure and composition of these complex DegPs. Until we get to sections 2.4 and 3 below, we can limit ourselves to examples in which the phrase after than rigidly designates a degree. The kinds of meanings I will assume for this case are defined in (5), assuming the definition of "maximum" in (6).

$$
\begin{aligned}
& \text { a. } \llbracket \text {-er than one foot } \rrbracket=\lambda \mathrm{P}<\mathrm{d}, \mathrm{t}>\cdot \max (\mathrm{P})>1^{\prime} \\
& \text { b. } \text { [exactly two inches } \text {-er than one foot } \rrbracket=\lambda \mathrm{P} . \max (\mathrm{P})=1^{\prime}+2^{\prime \prime}
\end{aligned}
$$

$$
\max (\mathrm{P}):=\text { td. } \mathrm{P}(\mathrm{d})=1 \& \forall \mathrm{d}^{\prime}\left[\mathrm{P}\left(\mathrm{d}^{\prime}\right)=1 \rightarrow \mathrm{d}^{\prime} \leq \mathrm{d}\right]
$$

Being of type $<\mathrm{dt}, \mathrm{t}>$, these complex DegPs cannot be interpreted in situ, but must move for interpretability to a position above the adjective's subject (not necessarily above the surface subject, if there are lower covert subjects). The movement leaves a trace of type $d$ and creates a $\lambda$-abstract of type $<d, t>$, which makes a suitable argument to the DegP. Here is a sample derivation.

(7) John is taller than 4 feet.

SS minus extraposition: John is [AP [DegP -er than $4 \mathrm{ft}$ ] tall]

LF: [DegP -er than $4 \mathrm{ft}]_{1}$ John is [AP $\mathrm{t}_{1}$ tall]

interpretation $^{4}: \max \{\mathrm{d}: \operatorname{tall}(\mathrm{j}, \mathrm{d})\}>4^{\prime}$

So John is taller than 4 feet is true iff the maximal degree to which John is tall exceeds 4 feet.

\section{DegP-scope and truth-conditions}

In the syntax and semantics just presented, I deliberately highlighted a close analogy between DegPs and DPs. In both categories, we find referring (and bound variable) phrases with denotations of a basic type (d or e) as well as quantificational phrases of the corresponding generalized quantifier type $(<\mathrm{dt}, \mathrm{t}\rangle$ or $<\mathrm{et}, \mathrm{t}>$ ). And in both, the quantificational phrases can move at LF, leaving behind basic-type traces and creating complex $\lambda$-predicates. In the case of DPs, this movement is known as QR (Quantifier Raising) and is standardly assumed to be the source of truth-conditional ambiguities. If DegPs are so similar in their LF-syntax and semantics, shouldn't we find analogous scope-ambiguities due to multiple choices of landing-sites for DegP-movement? For example, when a DegP originates in the surface-c-command domain of a quantificational DP, negation, or intensional predicate, it should be able to scope either below or above that item - at least as long as there is nothing in its path that is known to create islands for movement. In the present section, we try to test this prediction, by comparing the range of truth-conditionally distinct readings that we can generate by DegP-movement in our system with the readings that are actually possible. ${ }^{5}$ 


\subsection{Caveat: systematic equivalences and anomalies}

Not every scope ambiguity is a truth-conditional ambiguity. For example, when every boy scopes above every girl in the sentence Every girl saw every boy, the truth-conditions are just the same as when it scopes below it. The methodological implications of this fact are familiar. If we want to study the properties of $Q R$, we must choose our examples judiciously. The fact that this particular sentence has only one interpretation doesn't show that objects can't move over subjects.

When it comes to quantifiers over degrees rather than ordinary individuals, this point is especially pertinent. Due to the ordered structure of the domain of degrees and the monotonicity property of adjective meanings, there are lots of cases where the relative scopes of a DegP and another quantifier are indistinguishable. To get a feel for what I am talking about, consider a comparative with a universal subject DP.

$$
\text { Every girl is taller than } 4 \text { feet. }
$$

If the DegP -er than $4 f t$ is free to scope either below or above the subject, we have two LFs: a low-DegP LF as in (9)a and a high-DegP LF as in (9)b.
a. [every girl $]_{1}[\text {-er than } 4 \mathrm{ft}]_{2} \mathrm{t}_{1}$ is $\mathrm{t}_{2}$ tall
b. $[-e r \text { than } 4 \mathrm{ft}]_{2}$ [every girl $]_{1} \mathrm{t}_{1}$ is $\mathrm{t}_{2}$ tall

On the semantics specified above, these structures get the truth-conditions in (10)a,b respectively.

$$
\begin{aligned}
& \text { a. } \forall x\left[\operatorname{girl}(\mathrm{x}) \rightarrow \max \{\mathrm{d}: \operatorname{tall}(\mathrm{x}, \mathrm{d})\}>4^{\prime}\right] \\
& \text { b. } \max \{\mathrm{d}: \forall \mathrm{x}[\operatorname{girl}(\mathrm{x}) \rightarrow \operatorname{tall}(\mathrm{x}, \mathrm{d})]\}>4^{\prime}
\end{aligned}
$$

(10)a says that each girl's (maximal) height is above 4'. (10)b is less transparent at first: We form the set of degrees $d$ such that every girl is tall to $d$. Given the monotonicity of the tall-relation, this is precisely the set of degrees to which the shortest girl is tall (or the shortest girls, if two or more are tied for shortest). So the maximum of that is the (maximal) height of the shortest girl(s), and (10)b says this is above 4'. But that's the same claim as (10)a! If every girl is taller than 4', than the shortest girl is, and if the shortest girl is taller than 4', then every girl is.

Something similar happens when the subject is an existential quantifier. If we construct two LFs for (11) analogous to the ones in (9)a,b, we derive the truthconditions in (12)a,b.

(11) Some girl is taller than 4 feet.
a. $\exists x\left[\operatorname{girl}(x) \& \max \{d: \operatorname{tall}(x, d)\}>4^{\prime}\right]$
b. $\max \{\mathrm{d}: \exists \mathrm{x}[\operatorname{girl}(\mathrm{x}) \& \operatorname{tall}(\mathrm{x}, \mathrm{d})]\}>4^{\prime}$ 
In (12)b, we have the set of degrees d such that some girl is tall to $d$. This turns out to be the set of degrees to which the tallest girl is tall (or the tallest girls in the event of a tie). So (12)b says that the (maximal) height of the tallest girl(s) is above 4'. But if some girl is taller than 4', then the tallest one is, and if the tallest girl is taller than 4', then some girl is. So again (12)b winds up equivalent to (12)a. ${ }^{6}$

How pervasive is this kind of equivalence? Quite. It generalizes from comparatives to equatives. ${ }^{7}$ It generalizes from universal and existential to all monotone increasing quantifiers. And it generalizes from quantifiers over individuals to quantifiers over possible worlds. This means that we would be wasting our time trying to detect scope-ambiguities not only in examples like (8) and (11), but in any of the following as well.

(13) a. Every girl is as tall as John is.

b. Some girl is as tall as John is.

(14) a. More than 20 girls are taller than 4 feet.

b. Most of the papers are longer than 5 pages.

(15) a. The paper is required to be longer than 10 pages.

b. The paper is allowed to be longer than 10 pages.

Pick (15)a, for instance. required is a necessity operator, a universal quantifier over the set of accessible worlds (for some contextually given accessibility relation, plausibly here a deontic one). If the DegP -er than 5 pp scopes below required, our semantics delivers the truth-condition in (16)a, if the DegP scopes above required, we predict (16)b. ${ }^{8}$

$$
\begin{aligned}
& \text { a. } \forall \mathrm{w} \in \text { Acc: } \max \left\{\mathrm{d}: \operatorname{long}_{\mathrm{w}}(\mathrm{p}, \mathrm{d})\right\}>10 \mathrm{pp} \\
& \text { b. } \max \left\{\mathrm{d}: \forall \mathrm{w} \in \text { Acc: } \operatorname{long}_{\mathrm{w}}(\mathrm{p}, \mathrm{d})\right\}>10 \mathrm{pp}
\end{aligned}
$$

(16)a transparently says that the paper is longer than 10pp in every accessible world. (16)b instructs us to determine the maximal degree to which the paper is long in every accessible world. That is its (maximal) length in those accessible worlds where it is shortest (the 'minimal compliance' worlds, so to speak). This, (16)b says, exceeds 10pp - which is tantamount to (16)a, since if the paper exceeds $10 \mathrm{pp}$ in the accessible worlds where it's shortest, it exceeds $10 \mathrm{pp}$ in every accessible world, and vice versa. The reasoning is just as for every girl in (8). By the same token, the possiblity operator allowed in (15)b behaves just like some girl in (11). I leave it to the reader to establish the pertinent equivalences for the remaining examples.

So what have we learned so far about DegP-movement? Nothing yet. The examples we have analyzed here are consistent with everything we have assumed plus the assumption that DegP can move to any position where it is interpretable. They are also consistent with the possibility that DegP never moves beyond the lowest position where it is interpretable. We just couldn't tell. 
Our next set of examples will still not allow us to tell how far DegPs can move, but this time for a different reason. The high-DegP LF will not be equivalent to the low-DegP LF, but it will be semantically deviant and thus ruled out by independent principles. Consider scoping a DegP over a negation, as in the second LF given below for sentence (17)a.
a. Mary isn't taller than 4 feet
b. not [-er than 4'] Mary is $t$ tall
$\neg \max \{\mathrm{d}: \operatorname{tall}(\mathrm{m}, \mathrm{d})\}>4 \mathrm{ft}$
c. [-er than 4'] not [Mary is t tall] $\# \max \{\mathrm{d}: \neg \operatorname{tall}(\mathrm{m}, \mathrm{d})\}>4 \mathrm{ft}$

The predicted interpretation for (17)c refers to the maximum of the set of degrees to which Mary isn't tall. But that set has no maximum. ${ }^{9}$ So if such an LF can be generated, it is a presupposition failure. Plausibly, this suffices to explain why only one reading (the one in (17)b) is attested. For all we know, (17)c may or may not be generated by the syntax; even if it is, it will be filtered out.

This observation generalizes from plain negation to other implicitly negative or monotone decreasing operators.

(18) a. At most two girls are taller than 5 feet.

b. [at most two girls $]_{1}\left[-e r \text { than } 5^{\prime}\right]_{2} \mathrm{t}_{1}$ are $\mathrm{t}_{2}$ tall $\left|\left\{\mathrm{x}: \operatorname{girl}(\mathrm{x}) \& \max \{\mathrm{d}: \operatorname{tall}(\mathrm{x}, \mathrm{d})\}>5^{\prime}\right\}\right| \leq 2$

c. $\left[\text {-er than } 5^{\prime}\right]_{2}$ [at most two girls $]_{1} \mathrm{t}_{1}$ are $\mathrm{t}_{2}$ tall $\# \max \{\mathrm{d}:|\{\mathrm{x}: \operatorname{girl}(\mathrm{x}) \& \operatorname{tall}(\mathrm{x}, \mathrm{d})\}| \leq 2\}>5^{\prime}$

(19) a. (Mary works $60 \mathrm{hrs}$ a week, and) she refuses to work harder than that.

b. she refuses [[-er than that] PRO to work $\mathrm{t}$ hard] $\forall \mathrm{w} \in$ Acc: $\neg \max \{\mathrm{d}: \mathrm{m}$ works d-hard in $\mathrm{w}\}>60 \mathrm{hrs} / \mathrm{wk}$

c. [-er than that] she refuses PRO to work $t$ hard $\# \max \{\mathrm{d}: \forall \mathrm{w} \in$ Acc: $\neg \mathrm{m}$ works d-hard in $\mathrm{w}\}>60 \mathrm{hrs} / \mathrm{wk}$

As the reader can verify, the b-LFs capture the (only) available readings, and the c-LFs refer to undefined maxima.

If scoping over upward monotone operators always gives equivalent readings, and scoping over downward monotone ones always implies presupposition failure, we are left with the non-monotone ones.

a. Exactly two girls are taller than 5 feet.

b. [exactly two girls $]_{1}\left[-e r \text { than } 5^{\prime}\right]_{2} t_{1}$ are $t_{2}$ tall $\left|\left\{\mathrm{x}: \operatorname{girl}(\mathrm{x}) \& \max \{\mathrm{d}: \operatorname{tall}(\mathrm{x}, \mathrm{d})\}>5^{\prime}\right\}\right|=2$

c. $\left[\text {-er than } 5^{\prime}\right]_{2}$ [exactly two girls $]_{1} \mathrm{t}_{1}$ are $\mathrm{t}_{2}$ tall $\max \{\mathrm{d}:|\{\mathrm{x}: \operatorname{girl}(\mathrm{x}) \& \operatorname{tall}(\mathrm{x}, \mathrm{d})\}|=2\}>5^{\prime}$

The maximum referred to in (20)c turns out to be well-defined. In fact, the maximal degree to which exactly two girls are tall coincides with the maximal 
degree to which at least two girls are tall. So here we finally seem to have found a case that tells us something. The fact is that sentence (20)a unambiguously means (20)b and does not share a reading with the sentence At least two girls are taller than 5 feet. But if DegP is allowed to scope over the quantifier, as in (20)c, then such a reading is generated. So the analysis makes inadequate empirical predictions unless supplemented by some constraint on DegP-movement.

This is a fine argument given the assumptions I have adopted in this paper. It may not go through, however, in the context of a more comprehensive theory which incorporates an account of polar opposition along the lines of Bierwisch (1987) and Kennedy (1998). Briefly, (20)c may be ruled out by an independently motivated prohibition against sets of degrees which fail to be initial or final segments of the scale. Not being able to go into this, I leave it open here whether non-monotone operators can tell us anything about DegP-movement. ${ }^{10}$

\subsection{Exactly-differentials, less-comparatives, and Kennedy's generalization}

The equivalences observed in 2.1 hold for simple comparatives (and equatives) and also for comparatives with simple differential phrases, but they no longer hold for comparatives with a differential phrase containing at most or exactly (or for equatives modified by at most or exactly). Nor do they hold when we switch from more-comparatives to less-comparatives. For instance, we saw that if the shortest girl is taller than John, then every girl is. But if the shortest girl is exactly one inch taller than John, it doesn't follow that every girl is. And if the shortest girl is less tall than John, it also doesn't follow that every girl is. These and analogous non-equivalences will enable us to construct examples where the lowDegP and high-DegP LFs have clearly distinct yet equally non-deviant truthconditions, and where we can thus get empirical evidence about the availability of each LF.

Starting with exactly-differentials, consider the sentences in (21)a and (22)a and their predicted truth-conditions for LFs with low DegPs (b) and high DegPs (c).

(21) a. (John is 4' tall.) Some girl is exactly 1" taller than that.

b. [some girl] 1 [exactly $1^{\prime \prime}$-er than $\left.4^{\prime}\right]_{2} t_{1}$ is $t_{2}$ tall $\exists \mathrm{x}\left[\operatorname{girl}(\mathrm{x}) \& \max \{\mathrm{d}: \operatorname{tall}(\mathrm{x}, \mathrm{d})\}=4^{\prime}+1^{\prime \prime}\right]$

c. [exactly $1^{\prime \prime}$-er than $\left.4^{\prime}\right]_{2}$ [some girl] ${ }_{1} \mathrm{t}_{1}$ is $\mathrm{t}_{2}$ tall $\max \{\mathrm{d}: \exists \mathrm{x}[\operatorname{girl}(\mathrm{x}) \& \operatorname{tall}(\mathrm{x}, \mathrm{d})]\}=4^{\prime}+1^{\prime \prime}$
a. (...) Every girl is exactly $1 "$ taller than that.
b. $\forall \mathrm{x}\left[\operatorname{girl}(\mathrm{x}) \rightarrow \max \{\mathrm{d}: \operatorname{tall}(\mathrm{x}, \mathrm{d})\}=4^{\prime}+1^{\prime \prime}\right]$
c. $\max \{\mathrm{d}: \forall \mathrm{x}[\operatorname{girl}(\mathrm{x}) \rightarrow \operatorname{tall}(\mathrm{x}, \mathrm{d})]\}=4^{\prime}+1^{\prime \prime}$

The sentences are judged unambiguous, and the b-LFs correctly represent their intuitive meanings. What about the c-LFs? (21)c says, in effect, that the tallest girl is exactly 4' 1 ", which appears not to be a possible reading. Since it is a stronger claim than (21)b, though, it is a bit hard to prove that it's not an alternate 
reading. (Speakers may be reluctant to call something false when it's true on another reading.) But with the universal example (22)a, we don't have this methodological problem. (22)c expresses a weaker claim than (22)b. So we can construct scenarios in which $c$ is true while $b$ is false: just imagine that the shortest girl is exactly 4' $1^{\prime \prime}$ but some other girls are taller. If c were a possible reading of the English sentence, then speakers should sometimes be willing to judge it true in this situation. But it clearly is false. So (22)c cannot be a grammatical LF. The DegP apparently cannot scope over the quantificational DP.

Test cases with less lead to the same conclusion. Let us first make explicit the meaning of less-headed DegPs. The obvious rule is (23), which differs from the rule for -er just in the reversal of the $>$-relation.

$$
\text { \less than one foot } \rrbracket=\lambda \mathrm{P}<\mathrm{d}, \mathrm{t}>\max (\mathrm{P})<1^{\prime}
$$

Now consider low-DegP and high-DegP derivations for the sentence in (24)a.
a. (John is $4^{\prime}$ tall.) Every girl is less tall than that.
b. [every girl $]_{1}$ [less than $\left.4^{\prime}\right]_{2} t_{1}$ is $t_{2}$ tall $\forall \mathrm{x}\left[\operatorname{girl}(\mathrm{x}) \rightarrow \max \{\mathrm{d}: \operatorname{tall}(\mathrm{x}, \mathrm{d})\}<4^{\prime}\right]$
c. [less than $\left.4^{\prime}\right]_{2}$ [every girl] ${ }_{1} t_{1}$ is $t_{2}$ tall $\max \{\mathrm{d}: \forall \mathrm{x}[\operatorname{girl}(\mathrm{x}) \rightarrow \operatorname{tall}(\mathrm{x}, \mathrm{d})]\}<4^{\prime}$

(24)b transparently captures the intuitive meaning of the sentence. (24)c says that the shortest girl is less than 4' tall, which is a weaker claim than b and clearly not an available reading. Again, we must conclude that DegP doesn't scope over DP.

This holds not only for DPs in subject position. (25) has a universally quantified object, but still the DegP seems unable to scope over it.

(25) (The frostline is 3 and half feet deep.) Mary set every post exactly 2 feet deeper than that.

If exactly $2^{\prime}$-er than that took scope over every post, the sentence would be true if Mary set just the least deep post exactly $2^{\prime}$ below the frostline, but she set the other posts deeper. Intuitively, (25) is false in this case. Even in (26), where the quantified DP is an internal argument and to the right of the graded adjective, the DegP cannot scope over it.

(John gave every candidate an A.) ?Mary was less impressed with every candidate than that.

This cannot be true just because the candidate who impressed Mary the least didn't impress her enough to get an A. The generalization appears to be the one in (27), which I will refer to as "Kennedy's generalization".

(27) If the scope of a quantificational DP contains the trace of a DegP, it also contains that DegP itself. ${ }^{11}$ 
The most reasonable diagnosis at this point is that (27) holds generally, not just for the examples in this section, where DegP-scope happened to affect truthconditions. The examples in the previous section, where high DegPs yielded interpretations that were either truth-conditionally equivalent to low DegPs or semantically deviant, did not provide evidence for (27). But they were, of course, consistent with it as well.

\subsection{Intensional verbs and Stateva's argument}

In the last section we only looked at DegP-scope in relation to DP-quantifiers. What about intensional verbs? The logical point is the same: when we add exactly-differentials or switch form more to less, we ensure non-equivalence between low and high DegPs. Let's look at some examples and their predicted readings.

(28) a. (This draft is 10 pages.) The paper is required to be exactly 5 pages longer than that.

b. required [[exactly $5 \mathrm{pp}$. -er than that] the paper be $t$ long] $\forall \mathrm{w} \in$ Acc: $\max \left\{\mathrm{d}: \operatorname{long}_{\mathrm{w}}(\mathrm{p}, \mathrm{d})\right\}=15 \mathrm{pp}$

c. [exactly $5 \mathrm{pp}$. -er than that] [required [the paper be $\mathrm{t}$ long]] $\max \left\{\mathrm{d}: \forall \mathrm{w} \in \operatorname{Acc}: \operatorname{long}_{\mathrm{w}}(\mathrm{p}, \mathrm{d})\right\}=15 \mathrm{pp}$

(28)b says that the paper is exactly $15 \mathrm{pp}$ long in every acceptable world. This implies that it is not allowed to be longer than $15 \mathrm{pp}$. (28)c says that the paper is exactly $15 \mathrm{pp}$ long in those acceptable worlds where it is shortest. This leaves open whether it might also be allowed to be longer than $15 \mathrm{pp}$. The English sentence (28)a can be understood in either one of these two ways. It seems to be ambiguous, in just the way that we predict if the DegP can move either below or above the necessity operator. The same thing happens with a possibility operator.

(29) a. (..10 pp) The paper is allowed to be exactly 5 pages longer than that.

b. $\exists w \in$ Acc: $\max \left\{d: \operatorname{long}_{w}(p, d)\right\}=15 p p$

c. $\max \left\{\mathrm{d}: \exists \mathrm{w} \in \mathrm{Acc}:\right.$ long $\left._{\mathrm{w}}(\mathrm{p}, \mathrm{d})\right\}=15 \mathrm{pp}$

(29)b says that the paper is exactly $15 \mathrm{pp}$ in some acceptable worlds, leaving it open that it might also be allowed to be other lengths. (29)c says it is exactly $15 \mathrm{pp}$ long in the acceptable worlds where it is longest, which means it is not allowed to be longer than $15 \mathrm{pp}$. Again, these two distinct readings are both available for the English sentence (29)a.

Examples of intensional verbs with less-comparatives make the same point, as previously argued by Stateva (1999). ${ }^{12}$

(30) a. The paper is required to be less long than that.

b. required [[less than that] the paper be $t$ long] $\forall \mathrm{w} \in$ Acc: $\max \left\{\mathrm{d}: \operatorname{long}_{\mathrm{w}}(\mathrm{p}, \mathrm{d})\right\}<10 \mathrm{pp}$ 
c. [less than that] [required [the paper be $t$ long]] $\max \left\{\mathrm{d}: \forall \mathrm{w} \in \operatorname{Acc}: \operatorname{long}_{\mathrm{w}}(\mathrm{p}, \mathrm{d})\right\}<10 \mathrm{pp}$

(30)b says that the paper is less than 10pp in every acceptable world; so it's not allowed to be longer. But c says merely that it is less than 10pp in the acceptable worlds where it's shortest. $c$ is equivalent to 'the paper is not required to be as long as that'. Both of these clearly distinct readings are available. Similarly for the possibility sentence:

(31) a. (..10 pp) The paper is allowed to be less long than that.

b. $\exists w \in$ Acc: $\max \left\{\mathrm{d}: \operatorname{long}_{\mathrm{w}}(\mathrm{p}, \mathrm{d})\right\}<10 \mathrm{pp}$

c. $\max \left\{\mathrm{d}: \exists \mathrm{w} \in \mathrm{Acc}: \operatorname{long}_{\mathrm{w}}(\mathrm{p}, \mathrm{d})\right\}<10 \mathrm{pp}$

(31)c, which means that the paper is not allowed to be as long as $10 \mathrm{pp}$, is a possible reading for (31)a.

The availability of the c-readings in these examples indicates that DegP is not, after all, always confined to its narrowest possible scope. Intervening intensional verbs seem to differ from intervening quantificational DPs in this respect, and Kennedy's generalization does not carry over to them.

Or is there a different explanation for these ambiguities? These intensional verbs are known to participate in another strange phenomenon, the socalled scope-splitting of negative and other non-monotone-increasing quantifiers. $^{13}$ For example, No deposit is required means that it is not necessary to make a deposit, and At most three attempts are allowed means that it is not permitted to make more than three attempts. Maybe the c-readings of our comparative examples above are obtained not by DegP-movement, but by the same mechanism that splits scope in these cases. But what is that mechanism? Scope-splitting phenomena are not well understood and their analysis is controversial. One approach involves decomposition into a wide-scope negation and a narrow-scope residue, e.g. no deposit $=\mathrm{NEG}+a$ deposit, at most three attempts $=\mathrm{NEG}+$ more than three attempts, exactly 5pp -er than that $=\mathrm{NEG}+$ more than 5pp -er than that, less than that $=\mathrm{NEG}+$ as as that. But these decompositions are not all morphologically transparent (e.g., the last one involves a switch from the comparative to its dual, the equative). Another idea is to split off different wide-scope pieces in different cases, negation in some, focussensitive adverbs like only, exactly in others. But this would not seem to cover the less-cases. What I would like to suggest instead is that scope-splitting (at least sometimes) is DegP-movement. So I agree that the two phenomena are the same, but I question that there is a good analysis of scope-splitting that is a genuine alternative to DegP-scoping. Much more work is required to substantiate this suggestion. But assuming that I am on the right track with this, I tentatively conclude (with Stateva) that DegPs are able to scope over intensional verbs.

Does this hold for all intensional verbs? A wider range of examples reveals a mixed pattern. A few more verbs act just like require and allow, e.g. need and be able. (32)a,b are ambiguous in the same way as our examples above, and in particular permit the indicated high-DegP readings. 
a. John is able to run less fast than that. 'he is not able to run as fast as that'

b. The paper needs to be exactly 5 pp longer than that. 'the paper's required minumum length is exactly $5 \mathrm{pp}$ longer than that'

But the verbs below behave differently in that the high-DegP readings indicated are not attested.

(33) The paper might be less long than that.

*' it's not possible for it to be as long as that'

a. The paper should be less long than that.

*' it's not required for it to be as long as that'

b. The paper is supposed to be less long than that.

* 'it's not required for it to be as long as that'

c. I want the paper to be less long than that.

*' I don't require it to be as long as that'

Why the difference? There are two imaginable reasons. Either the intensional verbs in (33) and (34) just don't allow the DegP to move over them. Or there is something in their semantics that masks the truth-conditional effect of this movement. The second kind of explanation would be more interesting. I speculate that it is the right one for at least a subset of these examples. ${ }^{14}$ Notice that all the verbs in (34) are so-called neg-raising verbs: their outer negations are systematically understood as inner negations. For example, the paper shouldn't be coauthored means that it should be non-coauthored, and I don't want the paper to be coauthored means that I want it not to be coauthored. Could that have something to do with why the readings in (34) fail to surface?

Here is a very preliminary attempt to make such a connection. Suppose that "neg-raising" is due to a kind of excluded-middle presupposition ${ }^{15}$ : when we assert that $\mathrm{x}$ wants $\mathrm{p}$, we presuppose that $\mathrm{x}$ 's desires regarding $\mathrm{p}$ are determinate one way or the other, i.e., that $x$ either wants $p$ or wants not-p. Since the presupposition is inherited under negation, ' $x$ doesn't want $p$ ' conveys that $x$ wants not-p. When we embed a complement with a free degree-variable under want, then, the presupposition will generally not be fulfilled for all possible values of that variable. Suppose, e.g., that I want the paper to be at least 5 pages long and no longer than 7, but I don't care whether it is 5 or 6 or 7. Then I want the paper to be $d$-long is true for values for $d$ that are at or below 5 , and false for values above 7 , but neither true nor false for the ones in between (i.e., above 5 and not above 7). When we $\lambda$-abstract over $d$, then, we get a partial function of type $<\mathrm{d}, \mathrm{t}>$ which is undefined for the degrees in that middle zone.

How do comparative operators like -er and less work in this 3-valued semantics? Our old entries referred to the maximal degree of which $\mathrm{P}$ is true. In the bivalent setting, this is effectively the (sharp) border-line between the degrees that $P$ is true of and the degrees that $P$ is false of. It could have been equivalently referred to as the maximal degree of which $P$ is not false. Nothing we have said is 
affected if we change the definition of maximum, which the entries for -er and less rely on, from (6) above to (35) below.

$$
\max (P):=\text { the greatest lower bound }(\mathrm{glb}) \text { of }\{\mathrm{d}: \mathrm{P}(\mathrm{d})=0\}
$$

But see what we now get for the two LFs of sentence (34)c.

a. I want [[less than 10pp] the paper to be $t$ long]

b. [less than $10 \mathrm{pp}$ ] I want the paper to be $t$ long

(36)a means, as before, that the paper is less long than 10pp in every world which conforms to my desires. (It also now receives a presupposition, but one entailed by this assertion, which is indetectable.) (36)b, however, now means that the glb of the lengths which I want the paper not to be is below 10pp. This glb is the maximal length that $\mathrm{I}$ tolerate (not the maximal length that $\mathrm{I}$ require). So $\mathrm{b}$ is equivalent to a.

\subsection{DegP-scope and de re/de dicto ambiguity}

Some of the older literature on comparatives took for granted that the famous Russell ambiguity in (37) was a matter of DegP-scope.

John thinks the yacht is longer than it is.

When the DegP scopes below the verb think, it was assumed, we get the contradictory-thought reading, and the sensible reading is due to the DegP scoping above think. Stechow (1984) was the first to see clearly that this was a mistake. Analyzing examples like (38), he showed that a high-DegP LF would not only be an island violation, but also misrepresent the truth-conditions.

If Mary smoked less than she does, she would be healthier.

We conclude with von Stechow that the Russell-ambiguity is a matter of de re or de dicto interpretation of the than-clause. There is merely a one-directional connection with DegP-scope: a de dicto interpretation of the than-clause is possible only if the DegP is in the scope of the relevant intensional verb, but a de $r e$ interpretation is compatible with either wide or narrow DegP-scope.

To spell this out a bit more, I need to fill in a treatment of clausal complements to than (which I avoided in the examples so far). Following standard practice, I take than-clauses to be derived by wh-movement of a covert operator from the degree-argument position of an adjective. The trace is interpreted as a variable over degrees. The wh-clause as a whole may be treated in analogy with a free relative, as a definite description of a maximal degree.

$$
\llbracket w h_{1} \text { the bed is } t_{1} \text { long } \rrbracket=\max \{\mathrm{d} \text { : long }(\text { the bed, } \mathrm{d})\}
$$


(39) in conjunction with our meaning for -er predicts that the sentence John is taller than the bed is long is true iff the (maximal) degree to which John is tall exceeds the (maximal) degree to which the bed is long.

As for the de relde dicto distinction, I assume that LF-representations contain explicit world-arguments for each predicate, and that the world-argument of the restrictor of a quantifier may, but need not, be bound locally. So even if we only consider narrow scope for the DegP, sentence (37) has two LFs, which differ in the choice of world-variable in the than-clause. ${ }^{16}$
a. John thinks $\mathrm{w}_{\mathrm{w}} \lambda \mathrm{w}^{\prime}\left[\left[-\mathrm{er}\right.\right.$ than wh it is $\mathrm{t}$ long $\left.\mathrm{w}^{\prime}\right]$ the yacht is $t$ long $\left._{\mathrm{w}^{\prime}}\right]$ $\forall \mathrm{w}^{\prime} \in \operatorname{Acc}(\mathrm{w}): \max \left\{\mathrm{d}: \operatorname{long}_{\mathrm{w}}(\mathrm{y}, \mathrm{d})\right\}>\max \left\{\mathrm{d}: \operatorname{long}^{\prime}(\mathrm{y}, \mathrm{d})\right\}$
b. John thinks ${ }_{\mathrm{w}} \lambda \mathrm{w}^{\prime}\left[\left[-\mathrm{er}\right.\right.$ than wh it is $\mathrm{t}$ long $\left._{\mathrm{w}}\right]$ the yacht is $\mathrm{t}$ long $\left._{\mathrm{w}^{\prime}}\right]$ $\forall \mathrm{w}^{\prime} \in \operatorname{Acc}(\mathrm{w}): \max \left\{\mathrm{d}: \operatorname{long}_{\mathrm{w}^{\prime}}(\mathrm{y}, \mathrm{d})\right\}>\max \left\{\mathrm{d}: \operatorname{long}_{\mathrm{w}}(\mathrm{y}, \mathrm{d})\right\}$

(40)a expresses the contradictory de dicto reading and (40)b the sensible de re reading. As we see here, both readings are compatible with narrow DegP-scope, and therefore, Russell ambiguites cannot be used as evidence for scopal mobility of DegPs. ${ }^{17}$

But notice that the ambiguities presented in the previous section were not Russell ambiguities. I deliberately have been using phrases after than that rigidly pick out degrees, so the issue of de re vs. de dicto didn't arise in the first place. Even though they are restricted to intensional contexts, the ambiguities we saw with exactly-differentials and less-comparatives cannot be explained away as involving de re without wide DegP-scope.

We can, of course, contrive examples in which there are both DegP-scope and de relde dicto ambiguities.

\section{(41) The box is required to be less wide than it is tall.}

We expect three possible readings, and this is what we find. (41) can mean that, in order to satisfy the requirements, the box must be taller than wide. This reading is generated by leaving the DegP low and interpreting the than-clause de dicto. (41) can also mean that the box should be less wide than the height that it actually happens to be. On this reading, the requirements don't regulate the box's proportions, only its width. We obtain this interpretation by means of a low DegP and a de re than-clause. Finally, (41) can mean that the box isn't required to be as wide as its actual height. This reading has a high DegP and (therefore) a de re than-clause. There can be no such thing as a high-DegP, de dicto than-clause reading. In this respect, (41) contrasts with (42).

\section{(42) The box is not required to be as wide as it is tall.}

Recall that when the than-phrase is rigid, the high-DegP reading of less coincides in meaning with the negation of the corresponding equative. Given a de re reading of the than or as-clause, the high-DegP reading of (41) is equivalent to (42). But (42) also allows a reading not shared by (41), on which the as-clause is 
de dicto: (42) can mean that it isn't required for the box to be as wide as tall (i.e., that it is allowed to be taller than wide). These judgments may be too complex to build strong conclusions on. But if they are real, then we may also have an argument here against at least one version of a scope-splitting analysis, which would say that less is decomposed into negation and equative, and only the negation can outscope the intensional verb.

\section{DegP-scope and syntactic and semantic ellipsis}

\subsection{Syntactic ellipsis: VP-deletion}

A standard argument for QR (covert movement of DPs) is that it is needed to license ellipsis in examples which on the surface suffer from antecedent containment (henceforth AC). For example, the deleted VP in (43)a seems to have an antecedent (the matrix VP) which contains it and therefore is not identical to it. ${ }^{18}$ But after QR has applied, as in (43)b, AC is resolved and the two VPs match perfectly.

a. I read every book wh that you did readt.

b. [every book wh that you did $\mathrm{t}$ ] I read $t$

A completely analogous argument can be put forward for covert DegP-movement. In the SS of (44)a, the deleted VP is contained in its antecedent, the matrix VP. If covert DegP movement applies as in $(44) \mathrm{b}$, the result is a structure with no AC and properly matched VPs.

a. Mary ran faster than wh John did fast.

b. [-er than wh John did funt fast] Mary ran $t$ fast

The idea that DegP-movement is involved in licensing ellipsis in comparative clauses has a long tradition. ${ }^{19}$ One recent argument in its favor was presented by Wold (1995). Carlson (1975) had observed that ACD in relative clauses is degraded when the head of the relative clause is a weak indefinite, especially an existentially read bare plural. ${ }^{20}$

*John was climbing trees that Bill was.

Diesing (1992) explained this by her thesis that existential bare plurals do not QR, but remain inside VP to get bound by existential closure. Thus they cannot get out of the VP to resolve AC, and ellipsis cannot be licensed. But (as also noted by Carlson) existential bare plurals do allow ACD in comparative clauses.

(46) a. John was climbing higher trees than Bill was.

b. John was climbing more trees than Bill was. 
Diesing left this as a potential challenge for her account. Wold showed that there is no problem if AC can also be resolved by DegP-movement instead of QR.

[-er than wh Bill was elimbing $t$ high trees] John was climbing t high trees

The bare plurals in (46) can stay in VP, low enough to get caught by existential closure, while DegP moves high enough to license the ellipsis.

In the first part of this paper, we found some semantic and syntactic constraints limiting where DegPs can move. If DegP-movement is indeed a prerequisite for ellipsis licensing, these constraints should affect the range of possible ellipses and their interpretations. Let us see whether that is true.

One thing that we saw above was that DegP-movement cannot cross over a quantificational DP (Kennedy's generalization). So what will happen if we construct an example in which, on the one hand, DegP must move out of VP to resolve $\mathrm{AC}$, but on the other hand, there is an intervening DP-quantifier in that VP? (48) is a case in point.

John pushed every weight higher than Mary did.

What we expect is that the only grammatical derivation will be one in which the DP every weight first moves out of the VP, so that then the DegP can also move out of VP without crossing over it. (It will only cross over its trace, which is fine.) So we get the LF in (49).

every weight 1 [-er than wh Mary did push $t_{1} t$ high $]_{2}$ John pushed $t_{1} t_{2}$ high

(49) says that for every weight $\mathrm{x}$, John pushed $\mathrm{x}$ higher than Mary pushed $\mathrm{x}$. This is what the English sentence in (48) means, and indeed the only reading that it appears to have. The general prediction is that quantificational DPs must scope "out of the way" whenever they are in the path of a DegP containing an antecedent-contained elided VP. This has intricate empirical implications, which for the most part remain to be tested. For example, we predict an interference with sloppy-identity construals of pronouns in examples like (50).

I planted one of my trees deeper than you did.

If we are on the right track, (50) should only allow a pragmatically odd reading: I planted one of my trees deeper than you planted that same tree. It is not obvious that this is correct, but also not easy to say what other readings are possible. More work is called for here. ${ }^{21}$

We also observed that DegP doesn't scope over negation and other monotone decreasing items, since the resulting readings would systematically be presupposition failures. If DegP-movement is needed to resolve ACD, it follows that (51) is ungrammatical on any reading that takes the matrix VP headed by refuse to be the antecedent of the elided VP. 
*John refused to run faster than Mary did refuse to run $t$ fast

This is correct. (The only good reading for this surface string is that John refused to run faster than Mary ran. $^{22}$ ) However, it turns out that we would be making this correct prediction regardless of whether DegP-movement plays any role in ellipsis licensing. The reading indicated in (51) also involves a presupposition failure within the than-clause: there is no maximal degree $d$ such that Mary refused to run d-fast. This in itself rules out the intended construal of the elided VP, independently of any assumptions about how ellipsis is licensed. So the judgment in (51) is merely consistent with the hypothesis that DegP-movement is needed for ellipsis licensing; it does not help support it.

With those intensional verbs that we saw a DegP can cross, we get ambiguity of antecedent-size, as expected. (52) is from Williams (1974).

(52) a. My father tells me to work harder than my boss does.

b. My father tells me to work harder than my boss does thard

c. My f. tells me to work harder than my b. does tell me to work $t$ hard
a. John needs to drive faster than Mary does.
b. John needs to drive faster than Mary does drive fast
c. John needs to drive faster than Mary does need to drive $t$ fast

To bring out each of the two readings of (53), imagine two contexts. In the context for reading $b$, we are talking about what it takes for John to win the race. Here there is no absolute minimal requirement for the speed he needs to attain; what matters is that his speed exceed Mary's. In the context for reading c, we are discussing John's and Mary's chances of making it to Ithaca by $8 \mathrm{pm}$ tonight (at the latest). Since John is currently 300 miles away from Ithaca, whereas Mary is only 200 miles away, the minimal speed for him to make it exceeds the minimal speed for her to make it. (Notice that there is no requirement here on their relative speeds.)

Interestingly, this ambiguity of antecedent-choice carries over to examples with verbs which we found not to show truth-conditionally distinct high-DegP readings, like the neg-raising verb want. (54) is the variant of Williams' example analyzed in Sag (1976).

(54) a. Mary's father wants her to work harder than her boss does.

b. Mary's father wants her to work harder than her boss does work $t$ hard

c. M's $f$ wants her to work harder than her b does want her to thard

This indicates that DegP can, after all, scope over these verbs, and that the reason why we didn't see truth-conditional reflexes of this scoping (when looking at lessDegPs) must be in their semantics. So we really need to work out the link between neg-raising behavior and lack of DegP-scope ambiguity that I sketched at the end of section 2.3 . 
Williams and Sag used these examples to point out a correlation between ellipsis and availability of de dicto readings. The non-elliptical (or less elliptical) (55) allows a de dicto reading of the than-clause that is not shared by its elliptical counterpart (52)c.

My father tells me to work harder than my boss tells me to.

(55) can describe a state of affairs where my father tells me: "I don't care how many hours you work, but make sure it's more than whatever your boss demands. If he says you have to work 20 hours, work at least 21 ; if he tells you to work 30 , work 31; etc." (52)a cannot describe this scenario on any of its readings. The only reading it shares with (55) is a de re reading, where the embedded tell-clause is evaluated in the utterance world, not in the worlds conforming to what my father demands. I.e., (52)c has to mean that my boss imposes a certain minimum requirement for how hard I have to work, and my father imposes another one which is higher than that. Williams and Sag took this fact to support the hypothesis that ellipsis-licensing depends on DegP-scope. They reasoned on the basis of a naïve identifcation of de re and de dicto with wide and narrow scope respectively. As we saw in 2.4 above, this is not justified; there is only a onedirectional implication, namely that if the DegP's scope is wide, the than-clause must be read de re. But fortunately, it is only this direction of the connection that is required for their argument. If the DegP must scope over the matrix verb in order to license the broad construal of the ellipsis, then the than-clause gets carried along out of the matrix verb's scope and therefore can only be read de re. This is just what was observed.

We can confirm the correlation between ellipsis-size and DegP-scope even more directly by changing Williams' kind of example to a variant with less.

Mary needs to drive less fast than John does need to drive $t$ fast

When the elided VP is understood to be headed by need (as indicated), the DegP must scope over need, and the truth-conditions therefore are those of a negated equative ('she doesn't need to drive as fast he needs to drive'). This prediction is also correct.

What have we learned in this section? There is more fieldwork to be done in the area where ACD in comparative clauses interacts with Kennedy's generalization. Apart from this, it appeared that our previous conclusions about DegP-movement were at least consistent with the view that ellipsis-licensing relies on DegP-movement. Our last set of facts, about DegP-scope and ellipsissize in examples with intensional verbs, showed moreover that this combination of assumptions makes some interesting correct predictions. It is difficult, however, to draw stronger conclusions at this point. We have not given any consideration to alternative hypotheses, which might account for ellipsis-licensing without appeal to DegP-movement. Before we examine concrete versions of such alternative theories, we cannot know whether they would have any difficulty making the same correct predictions also. 
What such alternatives might there be? That depends, for one thing, on our background assumptions about VP-ellipsis in general. We have tacitly taken for granted here that an elided VP and its antecedent must have LFs that are identical up to possible differences in indices. ${ }^{23}$ If we consider the possibility that some less restrictive parallelism condition might be sufficient, there may be ways to establish the required parallelism without DegP-movement. ${ }^{24}$ Even if we stick to the strict (near-)identity condition we have been assuming, it is not obvious that DegP-movement is the only way to resolve AC. What about moving the entire $\mathrm{AP}$, as in (57)?

[[-er than wh John did $t]$ fast] Mary ran $t$

For this to be a viable alternative, we would need appropriate interpretive mechanisms to deal with the AP-sized traces and their binding in this structure. It is not at all obvious what exactly these should be, how they would affect the reasoning in section 2 , and whether this path in the end would lead to something substantively different from DegP-movement. ${ }^{25}$ It is incumbent upon me to deal with these questions, but not in the space of this paper.

\subsection{Semantic "ellipsis": superlatives and too}

As we just saw, it is difficult to make a strong argument for DegP-movement on the basis of facts about VP ellipsis, because one needs so many auxiliary assumptions. Part of the difficulty is that it is controversial just how this kind of ellipsis is licensed and how close the match between the missing VP and its antecedent has to be. To side-step this controversy, it would be useful if we could look at cases of what I will call here "semantic ellipsis". By this I mean a construction in which there aren't two parallel pieces of syntactic (LF) structure which stand in an anaphor-antecedent relation, but rather there is a single piece which however is used twice in the semantic calculation. Analyses of this kind have often been proposed as competitors for analyses in terms of syntactic ellipsis, notably for so-called Comparative Ellipsis ${ }^{26}$, but there we would be getting onto even more controversial ground. The constructions I will look at here are ones for which (to my knowledge, at least) a semantic-ellipsis analysis is the only kind of analysis on the market.

Consider the superlative.

John screamed (the) loudest.

(58) can be paraphrased by a comparative: John screamed louder than anyone else did. The LF of the comparative paraphrase contains two degree predicates, one in the matrix clause and one in the than-clause. The superlative has only a matrix clause and still manages to convey the same meaning. The following analysis reveals how. ${ }^{27}$ 

a. $\quad \llbracket-e s t \rrbracket=\lambda \mathrm{R}<\mathrm{d}$,et $>\lambda \mathrm{x} . \max \{\mathrm{d}: \mathrm{R}(\mathrm{x}, \mathrm{d})\}>\max \{\mathrm{d}: \exists \mathrm{y} \neq \mathrm{x}: \mathrm{R}(\mathrm{y}, \mathrm{d})\}$

b. LF for (58): John [-est 1 [scream $t_{1}$ loud]]

Notice that $\mathrm{R}$ (the denotation of -est's complement) is "used twice" in the calculation prescribed by entry (59)a. We use it to determine one set of degrees for John, and another one for everybody else.

Recall now our example (53) (repeated here as (60)a) and compare it with the analogous superlative in (60)b.

(60) a. John needs to drive faster than Mary does.

b. John needs to drive fastest.

The two readings we observed in (60)a are replicated in (60)b. Just amend the scenarios that I gave above to bring out each reading by the addition of a third person, say Bill. Then (60)b might mean that John needs to outdo both Mary and Bill (say, in order to win the race). Or it might mean that the minimal speed that John needs (to get to Ithaca by $8 \mathrm{pm}$ ) is higher than the minimal speeds needed by Mary or Bill (since they are already nearer to Ithaca). In the comparative example (60)a, the ambiguity clearly involved different-sized choices of antecedent for the VP-ellipsis. On the view that ellipsis-licensing requires LF-identity - but not independently of this view - this implied that the two readings also differed in the scope of the DegP. In the superlative variant (60)b, there is no ellipsis to resolve. So how do we generate the analogous two readings? The obvious way - and here the only one available to us - is by scoping the DegP. As the reader can verify, if we scope -est below need, as in (61)a, the entry in (59)a gives us the first reading, and if we scope it above, as in (61)b, it gives us the second one.

a. $\mathrm{John}_{1}$ needs [ $\mathrm{t}_{1}$-est ${ }_{2}$ to drive $\mathrm{t}_{2}$ fast]

b. John 1 -est ${ }_{2}$ needs $\left[t_{1}\right.$ to drive $t_{2}$ fast $]$

Our analysis of the ambiguity in the superlative examples is parallel to our analysis for the comparative variant: in both cases, we invoke DegP-movement across the intensional verb to obtain the second reading. So what is new here, what do we learn from the superlative example that we haven't already learned from the comparative one? The new point is that the evidence for DegPmovement needn't be contingent on assumptions about ellipsis-licensing. Whether or not you accept the relatively strict parallelism conditions on VPellipsis that imply that DegP must be able to move above need in (60)a, you can't get around this movement if you want to account for all the readings of (60)b.

For the same methodological reason, it may be useful to look at gradation constructions with so ... that, too, and enough. ${ }^{28}$ These also seem to involve "semantic ellipsis", in the sense that the material in the scope of the degreeoperator is used twice in the semantic calculation. For example, too tall roughly means 'taller than is compatible with certain (contextually given) goals or desires'. If John is too tall, he is taller than it is acceptable for him to be tall. Notice how the clause 'John (be) tall' appears twice in this paraphrase, once unmodalized to 
the left of than, and another time under a possibility operator to its right. The following entry for too makes this transparent in the double occurrence of $\mathrm{P}^{29}$

$$
\llbracket \text { too } \llbracket \rrbracket^{\mathrm{N}}=\lambda \mathrm{P}<\mathrm{s}, \mathrm{dt}>\cdot \max (\mathrm{P}(\mathrm{w}))>\max \left\{\mathrm{d}: \exists \mathrm{w}^{\prime} \in \operatorname{Acc}(\mathrm{w}): \mathrm{P}\left(\mathrm{w}^{\prime}\right)(\mathrm{d})=1\right\}
$$

Consider now an example like (63).

John needs (to have) too much money.

(63) has one reading where it means that what John needs is to have too much money. Imagine he is the type of person who only feels secure when he has more money than he can spend. Unless he has too much money (for him to spend), his (emotional) needs are not satisfied. But (63) also has another reading, where it means that John's financial needs are too high. Imagine that he has many financial obligations (mortgage, alimony, gambling debts, ...). He considers taking a job as a linguistics professor, but thinks better of it, since his needs regarding salary are too high. He needs too much money for him to be a linguist.

These two readings differ in the contextually supplied accessibility relation for the implicit possibility operator associated with too, but that is not their only difference. They also differ in the scope of too with respect to need. For the first reading, the LF in (64)a is adequate, but for the second one, it must be as in (64)b.

a. John 1 needs [too 2 [ $\mathrm{t}_{1}$ to have $\mathrm{t}_{2}$ much money]]

$\forall \mathrm{w} \in \mathrm{Acc}_{\text {need }} \max \{\mathrm{d}: \mathrm{j}$ has d-much money in $\mathrm{w}\}>$ $\max \left\{\mathrm{d}: \exists \mathrm{w}^{\prime} \in \operatorname{Acc}_{\text {too }}(\mathrm{w}): \mathrm{j}\right.$ has d-much money in $\left.\mathrm{w}^{\prime}\right\}$

b. too $_{2}\left[\mathrm{John}_{1}\right.$ needs $\left[\mathrm{t}_{1}\right.$ to have $\mathrm{t}_{2}$ much money] $\max \left\{\mathrm{d}: \forall \mathrm{w} \in\right.$ Acc $_{\text {need }} \mathrm{j}$ has d-much money in $\left.\mathrm{w}\right\}>$ $\max \left\{\mathrm{d}: \exists \mathrm{w} \in \mathrm{Acc}_{\text {too }}: \forall \mathrm{w}^{\prime} \in \operatorname{Acc}_{\text {need }}(\mathrm{w}): \mathrm{j}\right.$ has d-much money in $\left.\mathrm{w}^{\prime}\right\}$

Acc $_{n e e d}$ is meant to pick out the worlds in which John's needs are met. Acc too is different for each reading. For the intended interpretation of (64)a, let's say it maps each $\mathrm{w}$ to the set of worlds which are like $\mathrm{w}$ in the respects that determine spending limits and in which John spends all his money. So (64)a says that John's needs are met only if he has more money than for him to have is compatible with him spending it all. For the intended interpretation of (64)b, let Acc too map each $\mathrm{w}$ to the set of worlds in which people obey the laws in effect in $\mathrm{w}$ (without starving) and in which John is a linguist. Then (64)b says that John's financial needs are greater than for them to be is compatible with him being a linguist. The important point for our purposes is that what is incompatible with being a linguist is not having lots of money, but needing lots of money. This is why we need to scope too over need in order to capture this second reading properly.

Due to the multiple layers of modality and concomitant contextdependency, the analysis of this type of example is rather complex. Still, I think we can isolate the contribution that is made by the degree operator's scope in 
relation to the intensional verb. If so, then we have another way here of detecting DegP-scope without taking a stand on licensing-principles for syntactic ellipsis.

\section{Conclusion}

We have probed the scopal behavior of degree quantifiers, using direct evidence from truth-conditional ambiguity as well as more indirect evidence from the interpretation of elided material. The argumentation was incomplete and tentative in a number of places, but suppose the picture that began to emerge is right. Then DegPs are mobile, but they are not allowed to cross over quantificational DPs. This appears to be a syntactic constraint of some kind, because the prohibited scopings would not in any way be semantically deviant. And if our treatment of ellipsis licensing is right, it is not a constraint on the absolute length of movement, since non-quantificational DPs in the same domains (including QR-traces of quantifiers) can be crossed over. Rather it is a constraint that specifically targets interveners of a certain kind. The situation is thus highly reminiscent of the intervention effects in wh-questions studied by Beck (1996), although the precise connections remain to be explored. More data need to be investigated to decide whether the parallel really holds up. And most importantly, we need to work out a syntactic analysis in which the observed constraint has principled reasons.

\section{Endnotes}

*I would like to thank the following people for helpful discussion, information and feedback: Sigrid Beck, Rajesh Bhatt, Danny Fox, Martin Hackl, Roumi Izvorski, Chris Kennedy, Lisa Matthewson, Cécile Meier, Yael Sharvit, Penka Stateva, Arnim von Stechow, Zoltán Szabó, and Karina Wilkinson.

${ }^{1}$ This is probably wrong. For arguments that extraposition marks scope, see Williams (1974), Guéron \& May (1984), and Fox \& Nissenbaum (2000). The task of integrating those authors' insights with the results of the present paper is left for the future.

${ }^{2}$ I treat degrees as a separate basic type (label ' $d$ ').

${ }^{3}$ This is not the DegP of Abney, Kennedy, and other proponents of the "DegP hypothesis". For them, AP is an argument of Deg, whereas my DegP is an argument of A.

${ }^{4}$ Abbreviations: tall $(\mathrm{x}, \mathrm{d}):=\mathrm{x}$ is tall to degree $\mathrm{d}$. $\mathrm{j}:=\mathrm{John}$.

${ }^{5}$ This whole section closely follows the reasoning in Kennedy (1997). 2.1 and 2.2 more or less just replicate his examples, arguments, and conclusions. 2.3 and 2.4 contain differing facts and conclusions, but even there I will mostly mimic his logic of argument.

${ }^{6}$ What about infinite domains? If there were infinitely many girls, there might be no shortest ones and/or no tallest ones. In that case, the maxima referred to in (10)b or (12)b are undefined. So my real claim, more accurately, is that pairs like 
(10) and (12) are equivalent whenever these maxima are defined. For my methodological point, this qualification makes no difference. I assume (see right below) that the high-DegP LF is automatically ruled out when its interpretation refers to an undefined maximum. So even if we consider universal and existential quantifiers with infinite domains, there can be no detectable scope ambiguity.

${ }^{7}$ This is assuming the (standard) 'at least'-interpretation of equatives, on which Mary is as tall as John is true (though under-informative) when she is actually taller than him. A suitable meaning-rule for equative DegPs analogous to (5)a is: $\llbracket$ as as one foot $\rrbracket=\lambda \mathrm{P} . \max (\mathrm{P}) \geq 1^{\prime}$. As for exactly-equatives, see 2.2 below.

${ }^{8}$ Abbreviations: $\mathrm{p}:=$ the paper. longw $(\mathrm{x}, \mathrm{d}):=\mathrm{x}$ is long to degree $\mathrm{d}$ in world $\mathrm{w}$. $\operatorname{Acc}(w):=$ the set of worlds accessible from $w$. The world argument of Acc is suppressed when it is the utterance world.

${ }^{9}$ This way of ruling out reading c admittedly depends on the specific semantics for -er that I chose, which makes reference to maximality. (Maximalization in the interpretation of the than-clause is standard - see von Stechow 1984, Rullmann $1995 \mathrm{~b}$, but in the matrix clause it is not.)

${ }^{10}$ The set $\{\mathrm{d}: \mid\{\mathrm{x}: \operatorname{girl}(\mathrm{x}) \&$ tall $(\mathrm{x}, \mathrm{d})\} \mid=2\}$ in (20)c fails to be an initial segment of the set of all heights whenever there are more than 2 girls, because it does not contain the degrees to which the third-tallest girl is tall. The constraint in question is needed to account for what Kennedy calls "cross-polar anomaly".

${ }^{11}$ This formulation is intended to allow DPs that take scope inside an argument of the graded adjective. In (i)a,b, the underlined DPs can have narrower scope than DegP, but since they don't intervene between the DegP and its trace, they are not counterexamples to Kennedy's generalization.

(i) a. Every student showed up less often than that.

'it happened less often than that that every student showed up'

b. An earthquake is more likely than a snowstorm.

The only potentially genuine counterexamples to (27) that I could come up with involve indefinite complements to adjectives of distance, as in (ii).

(ii) Jaffrey is closer to an airport than it is to a train station.

${ }^{12}$ Stateva talks about superlatives with least, but the point is the same.

${ }^{13}$ See e.g. Jacobs (1980), Rullmann (1995), Larson et al. (1997), de Swart (1999).

${ }^{14}$ I have no story about (33) at this point, but I hope that it may turn out to be covered by a general analysis of epistemic modals, which apparently always seek widest scope. See von Fintel \& Iatridou (2000).

${ }^{15}$ This is like the "homogeneity presupposition" of von Fintel (1997).

${ }^{16}$ The free variable $w$ here stands for the utterance world (the evaluation world for the whole sentence). The idea that quantifiers can have narrow scope even when their restrictors are interpreted de re is widely accepted nowadays, not just for comparatives but (especially) for DP-quantifiers. Abusch (1994), for example, makes this point about an example like If every senator were a rancher instead, I'd be happy (which is transparently parallel to von Stechow's (38)). See also Percus (2000).

${ }^{17}$ In later work (1993, 1998), von Stechow reversed his earlier position and decided that (40)b was not, after all, sufficient to capture the sensible reading of 
(37). The problem he saw is that (40)b has a comparison in the complement of think, but intuitively the thought reported by (37) need not have a comparative content. E.g., John might just be thinking "the yacht is 14' long" (when in fact it is $13^{\prime}$ long). I don't see the force of this objection (at least not given the semantics I am assuming here). (40)b just says that in every doxastic alternative of John's, the yacht is longer than it is in the actual world. This is true if he thinks it is 14' long. Despite its form, (40)b does not actually say he has a comparative thought.

${ }^{18}$ I use strike-out to represent an elided VP with a certain intended interpretation.

${ }^{19}$ See Bresnan (1973), Sag (1976), among others.

${ }^{20}$ There is some doubt about the correctness of Carlson's descriptive generalization. According to Pesetsky (pc), at least some examples of this sort improve with the addition of too in the elliptical clause. This may undermine Wold's argument.

${ }^{21}$ To make sense of the facts in this area, it will be necessary, for one thing, to take a systematic look at the behavior of quantifiers inside the than-clause. There are well-known puzzles here, and a recent paper by Schwarzschild \& Wilkinson compellingly argues that they can only be solved if we change some of the basic assumptions that I have unquestioningly taken over from the literature. Obviously, I need to make my reasoning consistent with their insights somehow, and before I manage to do this, there is reasonable doubt as to whether this paper is even asking the right questions.

${ }^{22}$ This is a reading where the elided VP is headed by run and is interpreted de re. I.e., we are saying about Mary's actual speed that John refused to surpass it. It may be marginally possible also to get a de dicto reading, meaning that John refused to outrun Mary. That reading is easier if the auxiliary is changed from did to would, or (even better) if we switch to the Comparative Ellipsis variant with no auxiliary at all.

${ }^{23}$ See Rooth (1992) and work based on that for more detail on the assumptions about ellipsis licensing that underlie this requirement.

${ }^{24}$ E.g., it may suffice to move just the than-clause or the wh-clause after than:

(i) [wh John did run $t$ fast] Mary ran [-er than t] fast

The VPs are still not identical here, but AC is resolved. And as Kennedy (pc) points out, the existential closures of the two VPs are semantically equivalent $(\lambda \mathrm{x} . \exists \mathrm{d}[\mathrm{x}$ ran $\mathrm{d}$-fast $]=\lambda \mathrm{x} . \exists \mathrm{d}[\mathrm{x}$ ran faster than $\mathrm{d}])$, which suffices for ellipsislicensing according to a recent proposal by Merchant (1999). But this idea runs into a problem with differential phrases, as in Mary ran $5 \mathrm{~km} / \mathrm{h}$ faster than John did, where the analogous equivalence fails. $(\lambda \mathrm{x} . \exists \mathrm{d}[\mathrm{x}$ ran $\mathrm{d}$-fast $] \neq \lambda \mathrm{x} . \exists \mathrm{d}[\mathrm{x}$ ran $5 \mathrm{~km} / \mathrm{h}$ faster than $\mathrm{d}]$ ).

${ }^{25}$ One proposal for interpreting structures like (57) is worked out in Kennedy (1997). I will discuss this on another occasion.

${ }^{26}$ See e.g. the "direct analysis" phrasal comparatives in Heim (1985), and similar analyses for $\mathrm{CE}$ as well as related constructions like Bare Argument Ellipsis and Gapping that were defended by Reinhart \& Rooth (1986), Reinhart (1989), Kennedy (1997), and others. See also Lechner (1999) for critical discussion. 
${ }^{27}$ Heim (1985). In Heim (1999), I propose a variant that makes the semantic type the same as for the comparative and equative DegPs (by eliminating the external argument). This amendment would not affect the present reasoning.

${ }^{28}$ See Meier (2000) for a detailed investigation and semantic analysis of these constructions.

${ }^{29}$ The same point still holds when we consider examples where too selects a forinfinitival. The for-clause supplies an explcit restrictor for the modal operator introduced by too, but it does nothing to spell out its nuclear scope. So we still need to use DegP's sister twice, as shown in the following rule for too $+($ for- $) \mathrm{CP}$.

(i) $\llbracket$ too $\mathrm{CP} \rrbracket^{\mathrm{N}}=$ $\lambda \mathrm{P} . \max (\mathrm{P}(\mathrm{w}))>\max \left\{\mathrm{d}: \exists \mathrm{w}^{\prime} \in \operatorname{Acc}(\mathrm{w}): \llbracket C P \rrbracket^{\mathrm{w}^{\prime}}=1 \& \mathrm{P}\left(\mathrm{w}^{\prime}\right)(\mathrm{d})=1\right\}$

\section{References}

Abney, Stephen (1987) The English NP in its Sentential Aspect, Ph.D. thesis, MIT Abusch, Dorit (1994) 'The Scope of Indefinites,' Natural Language Semantics 2

Beck, Sigrid (1996) 'Quantified Structures as Barriers for LF Movement,' Natural Language Semantics 4

Bierwisch, Manfred (1987) 'Semantik der Graduierung,' in M. Bierwisch \& E. Lang (eds.) Grammatische und konzeptuelle Aspekte von Dimensionsadjektiven, Studia Grammatica 16, Berlin: Akademie-Verlag

Bresnan, Joan (1973) 'Syntax of the Comparative Clause Construction in English,' Linguistic Inquiry 4

Carlson, Gregory (1975) 'Amount Relatives,' Language 53

Diesing, Molly (1992) Indefinites, Cambridge: MIT Press

von Fintel, Kai (1997) 'Bare Plurals, Bare Conditionals, and Only,' Journal of Semantics 14

von Fintel, Kai \& Sabine Iatridou (2000) 'On the Interaction of Modals, Quantifiers, and If-Clauses,' ms. M.I.T.

Fox, Danny \& Jon Nissenbaum (2000) 'Extraposition and Covert Movement,' ms. Harvard Univ. and M.I.T.

Guéron, Jacqueline \& Robert May (1984) 'Extraposition and Logical Form,' Linguistic Inquiry 15

Heim, Irene (1985) 'Notes on Comparatives and Related Matters,' ms. Univ. of Texas, Austin

-- (1999) 'Notes on Superlatives,' ms. MIT

Jacobs, Joachim (1980) 'Lexical Decomposition in Montague Grammar,' Theoretical Linguistics 7

Kennedy, Christopher (1997) Projecting the Adjective, Ph.D. thesis, Univ. of California, Santa Cruz [also Garland Press 1999]

Larson, Richard, Marcel den Dikken, and Peter Ludlow (1997) 'Intensional Transitive Verbs and Abstract Clausal Complementation,' ms. SUNY Stonybrook 
Lechner, Winfried (1999) Comparatives and DP-Structure, Ph.D. thesis, Univ. of Massachusetts, Amherst

Meier, Cécile (2000) Konsekutive Konstruktionen und relative Modalität, doctoral thesis, Univ. Tübingen

Merchant, Jason (1999) The Syntax of Silence, Ph.D. thesis, Univ. of California, Santa Cruz

Percus, Orin (2000) 'Constraints on Some Other Variables in Syntax,' ms. Univ. Milano, to appear in Natural Language Semantics

Reinhart, Tanya (1989) 'Elliptic Conjunctions - Non-Quantificational LF,' in A. Kasher (ed.) The Chomskyan Turn, Oxford: Blackwell

Reinhart, T. \& Mats Rooth (1986) 'Taking Tiger Mountain by Strategy,' ms. Tel Aviv Univ. \& Univ. Stuttgart

Rooth, Mats (1992) 'Ellipsis Redundancy and Reduction Redundancy,' in S. Berman \& A. Hestvik (eds.) Proceedings of the Stuttgart Ellipsis Workshop, Univ. of Stuttgart

Rullmann, Hotze (1995a) 'Geen eenheid,' Tabu 25

--- (1995b) Maximality in the Semantics of WH-Constructions, Ph.D. thesis, Univ. of Massachusetts, Amherst

Sag, Ivan (1976) Deletion and Logical Form, Ph.D. thesis, M.I.T.

Schwarzschild, Roger and Karina Wilkinson (1999) 'Interval Semantics for Scalar Predication,' ms. Rutgers Univ.

Stateva, Penka (1999) 'In Defense of the Movement Theory of Superlatives,' ms. Univ. of Connecticut, Storrs, to appear in ESCOL

von Stechow, Arnim (1984) 'Comparing Semantic Theories of Comparison,' Journal of Semantics 3

--- (1993) 'Die Aufgaben der Syntax,' in J. Jacobs et al. (eds.) Syntax - A Handbook of International Research, Berlin: de Gruyter

--- (1998) 'Some Remarks on Ch. Kennedy's Syntax and Semantics of Comparison', ms. Univ. Tübingen (presented at Workshop "Syntax and Semantics of Comparatives", Berlin)

de Swart, Henriette (1999) 'Scope Ambiguities with Negative Quantifiers,' in K. v. Heusinger \& U. Egli (eds.) Reference and Anaphoric Relations, Dordrecht: Kluwer

Williams, Edwin (1974) Rule Ordering in Syntox, Ph.D. thesis, M.I.T.

Wold, Dag (1995) 'Antecedent-Contained Deletion in Comparative Constructions,' ms. M.I.T. 